\title{
Clinical and Electromyographic Examinations of Patients with Essential Tremor
}

\author{
Ivan Milanov
}

\begin{abstract}
Background: It is believed that no clinical differences exist among essential, familial and senile tremor, or between the tremor with synchronous or alternating electromyographic activity. The aim of this study was to evaluate the clinical and electromyographic findings in a large group of patients with different types of essential tremor. Methods: Two hundred and twenty patients with sporadic, familial or senile variants of essential tremor were examined. According to the electromyographic activity recorded from the antagonistic muscles, the patients were subdivided into a group with synchronous (SYN) and a group with alternating (ALT) activity. The historical aspects of the disease were noted, and a detailed neurological examination was performed. Results: A widespread tremor involving upper and lower limbs and 3-4 different anatomical regions was typical for familial tremor. It also had higher amplitude than the sporadic and senile tremor. ALT tremor had a higher amplitude and longer burst duration than SYN and more often involved lower limbs. Rest tremor was common in the ALT group. Overall, ALT tremor was more common than previously supposed. Conclusion: The familial and ALT tremors are more disabling than other types of essential tremor. Since electromyographic ALT activity is common in essential tremor, its presence does not reliably distinguish essential and Parkinsonian tremor.
\end{abstract}

RÉSUMÉ: Examen clinique et électromyographique des patients atteints de tremblement essentiel. Introduction: On croit généralement qu'il n'existe pas de différences cliniques entre le tremblement essentiel, familial ou sénile ainsi qu'entre le tremblement avec activité synchrone ou alternante à l'électromyographie. Le but de cette étude était de réévaluer les observations cliniques et électromyographiques d'un groupe de patients ayant différents types de tremblement essentiel. Méthodes: Deux cent vingt patients présentant un tremblement essentiel sporadique, familial ou sénile ont été examinés. Selon l'activité électromyographique enregistrée au niveau de muscles antagonistes, les patients ont été subdivisés en deux groupes: ceux avec activité synchrone (SYN) et ceux avec activité alternante (ALT). Les aspects historiques de la maladie ont été notés et les patients ont subi un examen neurologique détaillé. Résultats: Le tremblement généralisé impliquant les membres supérieurs et inférieurs et 3 ou 4 régions anatomiques différentes était typique du tremblement familial. Ce tremblement avait également une plus grande amplitude que le tremblement sporadique et le tremblement sénile. Le tremblement avec ALT avait une plus grande amplitude et des accès de tremblement plus longs que le tremblement SYN. Il impliquait plus souvent les membres inférieurs et un tremblement de repos était souvent présent. Le tremblement ALT était plus fréquent qu'on ne le pensait antérieurement. Conclusion: Les tremblements familial et ALT sont plus invalidants que les autres types de tremblement essentiel. L'activité alternante qu'on retrouve fréquemment soulève la question de l'utilité de l'ÉMG pour différencier le tremblement essentiel du tremblement parkinsonien.

Can. J. Neurol. Sci. 2000; 27: 65-70

Tremor is the most common movement disorder. ${ }^{1}$ There are a number of different types of tremor that are often confused with one another. Essential tremor is one of the most common types. ${ }^{1}$ Although strict clinical criteria have been proposed, ${ }^{2}$ essential tremor is often misdiagnosed as Parkinsonian tremor. ${ }^{3}$ Differentiation of Parkinsonian and essential tremor by electromyography is unclarified. .,5,6 $^{-1}$

Although it is believed that no differences exist among essential, familial and senile tremor, ${ }^{7,8}$ some clinical and neurophysiological differences have recently been reported. ${ }^{9,10}$
The clinical presentation of essential tremor is variable. ${ }^{1}$ Different classifications have been proposed ${ }^{11,12,13}$ and different clinical forms have been described. ${ }^{14,15,16}$ Electromyographic examination is able to distinguish synchronous (SYN) and

From the University Neurological Hospital-IV kilometre, Sofia, Bulgaria. RECEIVED DECEMBER 11, 1998. ACCEPTED IN FINAL FORM OCTOBER 18, 1999. Reprint requests to: Ivan Milanov, University Neurological Hospital-IV kilometre, III Neurological Clinic, Blvd. Tzarigradsko shosse-IV kilometre, Sofia 1113, Bulgaria 
alternating (ALT) tremor that may have distinct pathophysiological mechanisms. ${ }^{17,18}$ Clinical differences between these two types of tremor have also been reported. ${ }^{19}$ The usefulness of electromyographic examination, however, for differentiation of tremor subtypes is controversial. ${ }^{4,5,6,20}$ Recently, it has been proposed that different underlying movement disorders, that present with similar clinical signs, are included in the overall group of patients with essential tremor. ${ }^{11}$

The aim of this study was to evaluate clinical and electromyographic patterns in a large group of patients with different types of essential tremor.

\section{Patients ANd methods}

All 220 patients (126 female, 94 male) fulfilling the criteria for definite or probable essential tremor ${ }^{2}$ were included in this study. Patients were subdivided into three groups according to the data for sporadic, familial or senile variants of essential tremor. Patients with a family history of tremor, irrespective of the age symptoms first appeared, were included in the familial group. Patients with onset of the disease after the age of 65 and lacking a family history of tremor were included in the senile group. ${ }^{8,9}$ The remaining patients were included in the sporadic group.

The historical aspects of the disease were noted regarding onset of the disease, localisation of first symptoms, progression (tremor enhancement, involvement of new body parts, appearance of tremor in new limb positions), improvement with alcohol, and associated diseases. The dominant limb was assessed by the Edinburgh Handedness Inventory. ${ }^{21} \mathrm{~A}$ neurological examination was performed. The tremor was studied clinically with the limbs, head and body fully supported against gravity (rest), and with the hands outstretched (postural). The postural leg, head and body tremor was tested in an upright position. The kinetic tremor was tested during limb (using fingernose or heel-shin testing) movements, and the intention tremor was examined when the limb approached a target. In each position tremor of the most involved body part was graded on 03 Webster Tremor Scale. ${ }^{22}$ The anatomic distribution of the tremor was noted.

Surface electromyographic recordings (EMG) of the most involved limb in all positions were performed in all patients. The tremor activity was recorded by a pair of electrodes from the antagonistic groups of muscles that control wrist movement. The electrodes were positioned 3 $\mathrm{cm}$ apart in a longitudinal direction over the extensor carpi radialis and flexor carpi ulnaris muscles. ${ }^{23}$ Each recording session for a given limb position lasted five minutes followed by five minutes rest. Leg tremor was recorded from antagonistic groups of muscles of the leg (tibialis anterior and triceps surae). Head tremor was recorded from both sternocleidomastoid muscles. Chin, tongue, voice, and body tremor was not examined by EMG. The tremor frequency $(\mathrm{Hz})$, mean amplitude $(\mathrm{mV})$, burst duration (msec), and pattern (synchronous or alternating) were assessed. The amplitude was measured peak-to-peak for each burst and the mean value was calculated. The burst duration was measured for each burst and the mean value was determined. The examination was performed at the same time (11 a.m.) for all patients. ${ }^{24}$ They were asked not to use alcohol the previous evening and caffeine beverages or tea on the morning of the examination. They were all free of drugs known to influence tremor for seven days prior to the examination. The examination was performed in a quiet room after allowing enough time for the patients to become familiar with the surroundings. The EMG examination was repeated 20 days later.

According to the pattern of electromyographic activity recorded from the antagonistic muscles, the patients with sporadic, familial or senile tremor were further subdivided into two groups. Patients with synchronous patterns were included in subgroup SYN of sporadic, familial or senile tremor. Patients with alternating activity were included in subgroup ALT of sporadic, familial or senile tremor.

MANOVA and one-way ANOVA with post-hoc NewmanKeuls analysis were used to compare the data from the electromyographic examination. The Kruskall Wallis H-test was used to compare the data from the clinical tremor scoring. For both tests the differences were considered significant if $\mathrm{p}<$ 0.001. The Chi-square test was used for comparing the distribution of clinical signs between patients. The differences were considered significant if $\mathrm{p}<0.05$.

\section{RESUltS}

Familial tremor was identified in 113 patients, sporadic tremor in 73, and senile tremor in 34 patients. SYN tremor was found in 130 patients (38 sporadic, 72 familial and 20 senile), while ALT tremor was recorded in 90 patients (35 sporadic, 41 familial and 14 senile).

The mean patient age was $62.1 \pm 14.3(\mathrm{SD})$ years, and the mean duration of the tremor was 13 years. The mean age at onset was 49.1 \pm 18.2 (SD) years. No significant differences existed between patients with sporadic or familial tremor, or between SYN or ALT tremor with regard to mean age, duration and age at onset of the disease. None of the tremor subtypes had a gender predeliction.

A similar percentage of sporadic and familial patients had

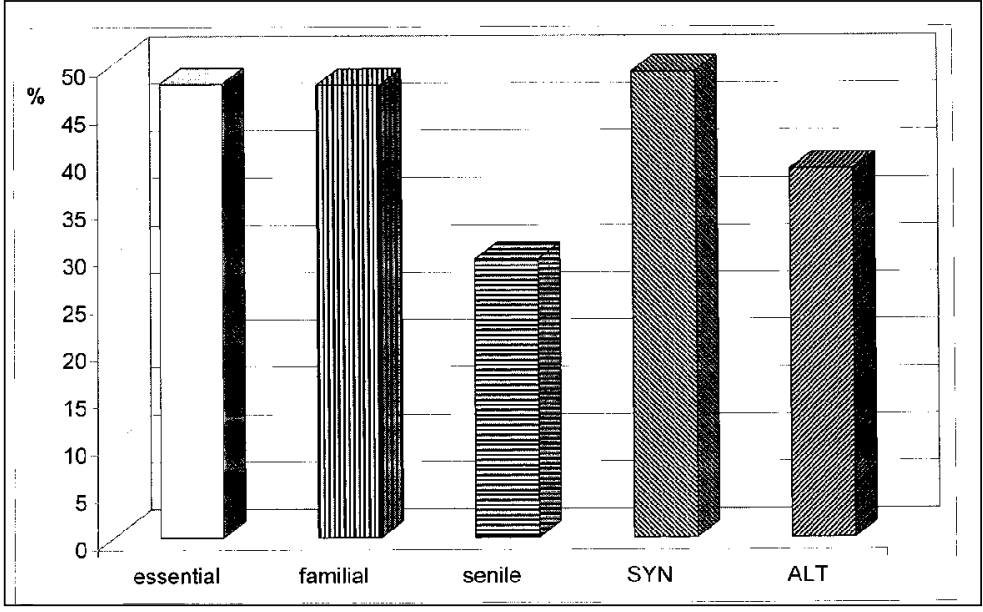

Figure 1: Alcohol influence on tremor. Percentages of patients reporting benefit of alcohol are indicated. SYN tremor with synchronous EMG pattern; ALT tremor with alternating EMG pattern. 


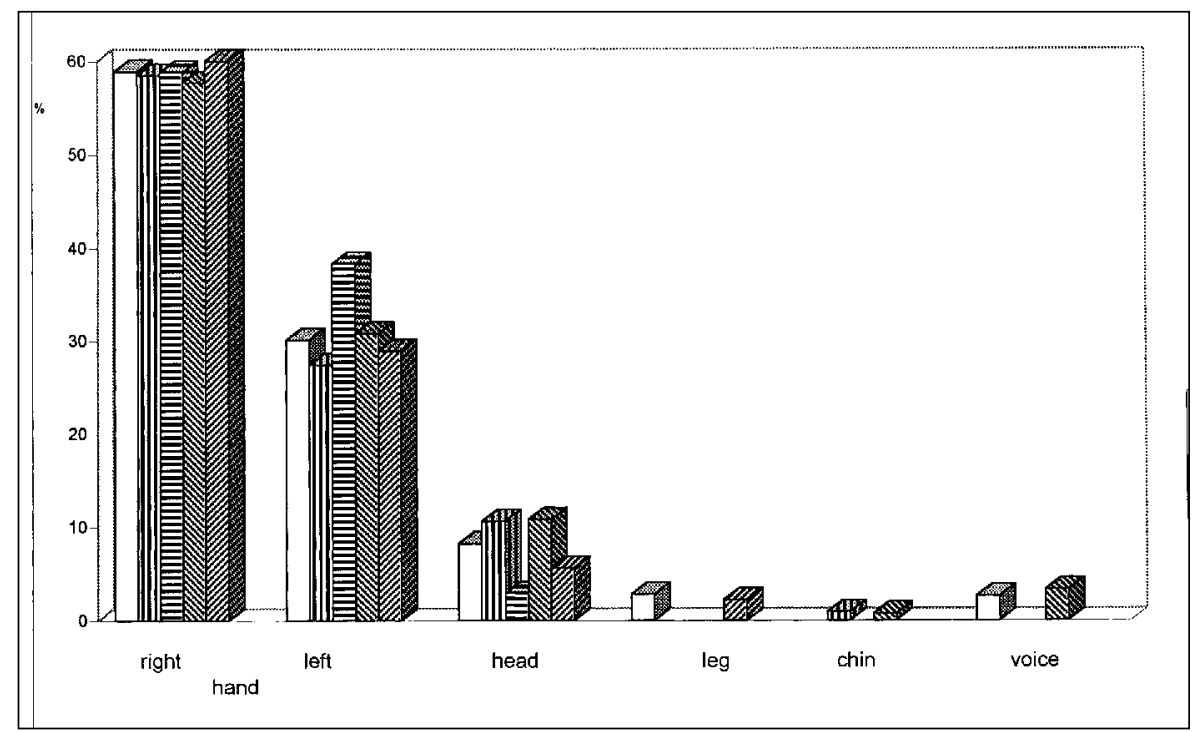

Figure 2: Onset of the disease from different body parts. Percentages of patients reporting onset of the disease from particular body part are indicated. SYN tremor with synchronous EMG pattern; ALT tremor with alternating EMG pattern.

improvement with alcohol while senile tremor patients rarely reported this effect (Figure 1). Alcohol improved more patients with SYN than ALT tremor.

The onset of the disease for most patients was in one hand, and rarely the head (Figure 2). More often the right (dominant) hand was the first involved and about $97 \%$ of our patients were right-handed. An onset of tremor outside the limbs was found only for familial and ALT tremor, and from the legs was only observed for sporadic and ALT tremor patients.

The progression of the disease was slow with no differences between groups. Patients reported an exacerbation of their tremor after a mean of 4.6 years and involvement of a new anatomical region after a mean of 5.8 years. Tremor in a new limb position appeared after a mean of 5.6 years. Usually patients reported the appearance of intention tremor later.

Tremor of both hands was the most common pattern for all groups of patients (Figure 3). The tremor, however, was not symmetrical and was prominent in the hand that had earliest involvement. Involvement of the limbs in association with other body parts was rarely found. All four limbs were more frequently involved in familial and ALT tremor patients, while only one limb was more frequently involved in senile tremor patients.

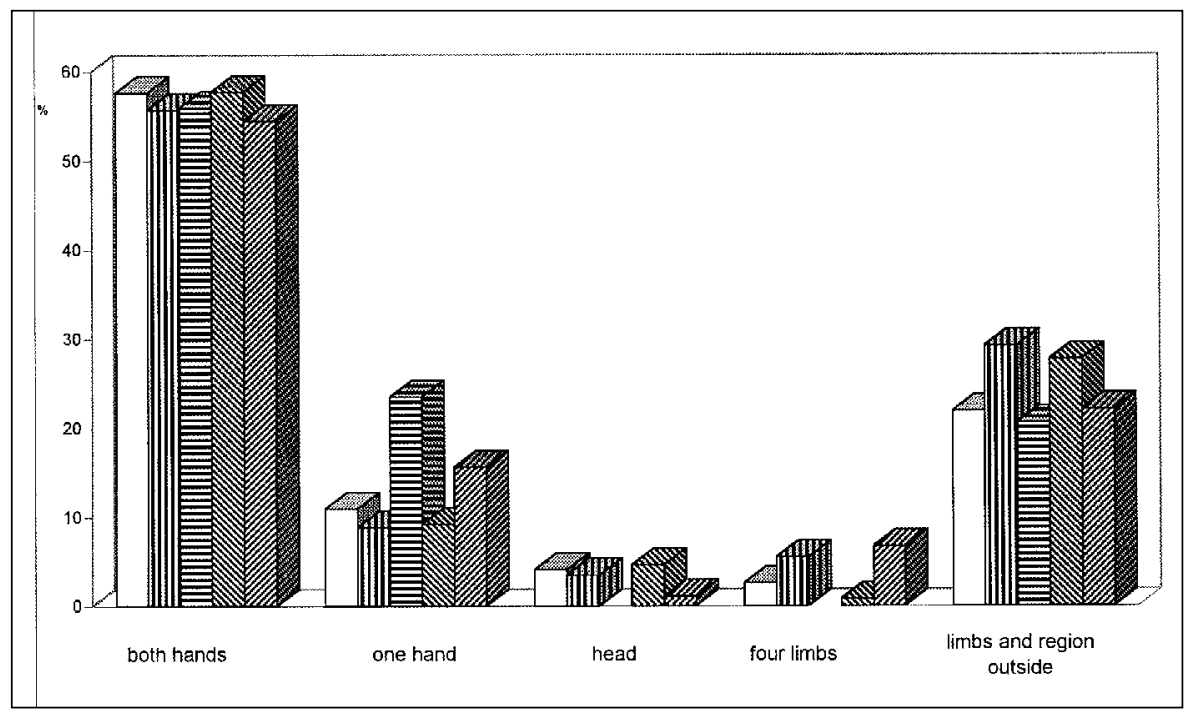

Figure 3: Tremor localization in different body parts. Percentages of patients with tremor in different body parts are indicated. The tremor localization is evaluated during the neurological examination. SYN tremor with synchronous EMG pattern; ALT tremor with alternating EMG pattern. 
Table: Results of the EMG examination

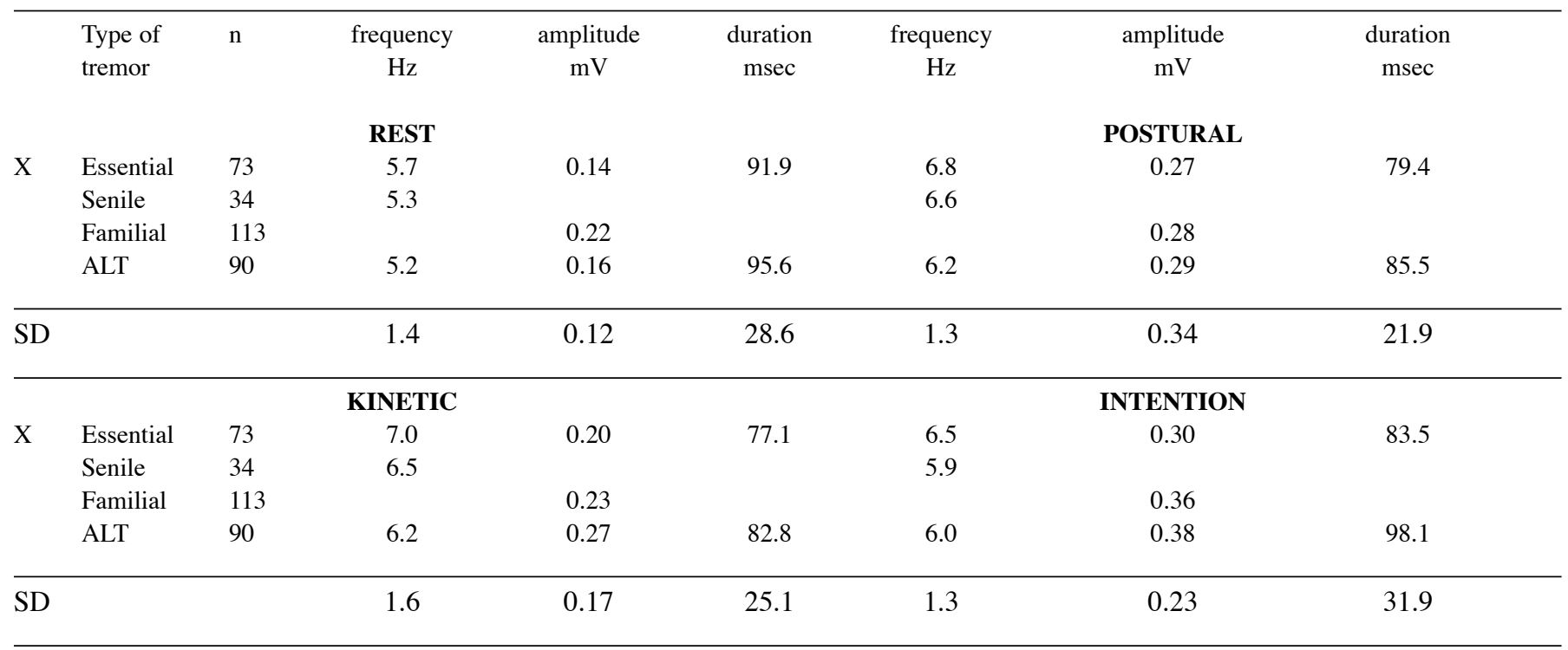

$\mathrm{X}$-mean value; SD-standard deviation; frequency-tremor frequency; amplitude-tremor amplitude; duration-bursts duration

For familial, senile and ALT tremor only mean values that are significantly different from overall essential tremor mean values are included. SYN tremor mean values are not included because they were not significantly different from overall essential tremor mean values.

Other body parts were more frequently involved in familial and SYN tremor patents.

One or, rarely, two body regions, as well as both hands were frequently involved in most patients. Patients with familial tremor had widespread involvement of three or four body parts. There was a tendency for earlier involvement of regions outside the limbs in patients with SYN tremor and for all the limbs involved in ALT tremor. The head was more frequently involved in SYN tremor, while the chin, tongue and body were more common in ALT.

The regions, other than the limbs, most involved were the head $(19.1 \%)$, voice $(10.4 \%)$, chin $(3.6 \%)$ and body $(2.7 \%)$. Tongue tremor was rare $(0.8 \%)$, found only in familial and ALT patients.

Postural and kinetic, or postural, kinetic and intention tremor presented most frequently. Isolated postural tremor was rarely found. Combined resting, postural, kinetic and intention tremor was found only in ALT patients. Isolated intention tremor was found only in familial tremor patients.

In a majority of patients (59.1\%), the EMG recordings revealed tremor with a synchronous activity (SYN) in the extensor and flexor muscle groups. In $40.9 \%$ of the patients, tremor with alternating EMG activity (ALT) was found. No differences existed between the number of SYN or ALT tremor patients in sporadic and senile tremor groups. SYN tremor $(63.7 \%)$ was found more frequently than ALT $(36.3 \%)$ in familial tremor patents. The synchronous and alternating pattern in individual patients persisted in all limb positions. In some patients, short-lasting changes in pattern appeared only during the transition from one limb position to another. The repeat tremor measurements revealed no significant changes in tremor pattern, frequency or burst duration. Although some variations in tremor amplitude were noted, they were not significant.

Rest tremor was found only in patients with ALT tremor and had the lowest amplitude and frequency (Table). The intention tremor had the highest amplitude. No differences existed between parameters of the postural and kinetic tremors, and both these tremors had the highest frequencies. The rest and intention tremors had longer burst durations.

The frequency of the senile tremor was lower. The amplitudes of familial and ALT tremors were higher. The frequency was lower, while the burst duration was longer in ALT tremor patients.

Clinical tremor scoring confirmed the amplitude data obtained by EMG examination.

\section{DiscuSSION}

The patients presented here were selected by their referral to our Movement Disorders Department, and may not represent a general population of essential tremor patients. Patients with more severe essential tremor were more likely to visit the clinic.

It has been suggested that essential tremor involves men more frequently than women ${ }^{25,26}$ but no gender differences were found in our study. We were also not able to confirm an earlier study showing a greater incidence of essential tremor in left-handed patients. $^{32}$

Our data confirmed that tremor was familial in approximately $50 \%$ of patients, ${ }^{8,26,27}$ while $100 \%$ inheritance has also been reported. ${ }^{28}$

Although the onset of tremor is reported to be earlier in the familial than in the sporadic form, ${ }^{7,8,29}$ we did not confirm this. It is known that tremor is slowly progressive, and becomes 
moderately severe after about 15 years. ${ }^{3}$ Patients with sporadic and familial tremor were referred to our clinic at about the same time after disease onset, when the tremor began to disturb daily activities.

Small amounts of alcohol induce temporary relief of tremor in $60-80 \%$ of patients. ${ }^{3,7}$ There is controversy regarding whether this phenomenon is more pronounced for patients with SYN tremor ${ }^{6}$ or not. ${ }^{30}$ Some authors have even suggest that alcohol has no influence on tremor. ${ }^{31}$ Our results noted improvement with alcohol in about half of the patients. More patients with SYN tremor reported this effect. Fewer patients with senile tremor had diminished tremor with alcohol but these patients may use only small, infrequent amounts of alcohol and may be unable to assess its effects.

Our data confirmed the reports that essential tremor usually originates from the dominant hand. ${ }^{29,32}$ Occasionally the head is affected first, but other sites of onset are rare. ${ }^{3}$ We also found that unilateral hand tremor usually spreads to the contralateral hand or to the head ${ }^{3,29}$ and although with time both hands are involved, it remains asymmetric. ${ }^{8}$ Our findings are in line with previously reported data that isolated hand tremor occurs most often, while the association with head, voice, lip and leg tremor is less common. ${ }^{7,26,29}$ Isolated cranial tremor or unilateral hand tremor was rare. ${ }^{29}$ We found that of the cranial musculature, head tremor was most frequent, followed by voice tremor. ${ }^{7}$ We confirmed in the later stages of the disease the legs and trunk may occur, albeit infrequently. ${ }^{29}$ The characteristic anatomic distribution of essential tremor is reported to be helpful for differentiation from Parkinsonian tremor. ${ }^{7}$

It has been reported that postural tremor is most pronounced in patients with essential tremor, and only in some patients is the tremor more marked during movement, or as the limb approaches the target. ${ }^{3,33}$ In contrast, our data revealed that intention tremor was most pronounced, followed by postural and kinetic tremors equally expressed. Our data indicated that with the progression of the disease, tremor in new limb positions appeared. Usually postural tremor appeared first, followed by kinetic and later intention tremors. Rest tremor was last to appear. An essential tremor variant with predominantly rest and lower postural tremor has been reported. ${ }^{14,34}$ We were not able to find a patient with a predominantly rest tremor. A prominent kinetic form with kinetic and intention features has also been reported. ${ }^{15,18,34} \mathrm{We}$ found this form in some patients with isolated intention, or kinetic and intention tremor. We did not identify patients with the reported pattern of rest and postural tremor in the legs. ${ }^{16}$ It has also been suggested that this variant represents a combination of essential and Parkinsonian tremor. ${ }^{35}$

The results from the EMG examination confirmed reported physiological characteristics of essential tremor: $5-9 \mathrm{~Hz}$ tremor frequencies, ${ }^{26,33} 50-100 \mathrm{msec}$ burst durations and a mean amplitude of $0.2 \mathrm{mV} .^{6,26}$ The intention tremor was the most disabling tremor, not only because it interfered with limb movements, ${ }^{15}$ but also because of its higher amplitude and longer burst duration.

It has been suggested that the electromyographic pattern in an individual patient may vary and cannot be used for differentiation of essential and Parkinsonian tremor. ${ }^{4,5,6}$ However, our results revealed that the tremor frequency and pattern do not change over time in the individual patient. Only some fluctuations in the tremor amplitude occurred, usually at the beginning of the examination.

It has also been reported that no clinical, physiological or therapeutic differences exist between sporadic, familial and senile tremor. ${ }^{7,8}$ Some clinical and neurophysiological differences have been recently reported $\mathrm{d}^{9,10,36}$ and our results also noted clinical and neurophysiological differences between the tremor types. Isolated head, voice or chin tremor is reported to be found more often in familial cases. ${ }^{36}$ Our results indicate that these types of tremor are not only more frequent in the familial tremor, but the voice and chin tremor was often present at the onset. Widespread tremor involving upper and lower limbs and 3-4 different anatomical regions was also typical. Thus we can confirm previous reports that unilateral tremor is more frequent in sporadic cases, whereas bilateral tremor is more common in familial cases. ${ }^{10}$ Moreover, the rest and intention familial tremors had the highest amplitude, as compared to sporadic and senile tremor patients. Our data did not confirm a report of higher frequency and lower amplitude in familial tremor. ${ }^{10}$ Thus we may conclude that the familial tremor is more disabling. With the progression of essential tremor, not only is the tremor amplitude increased, but new anatomical regions become involved. ${ }^{3}$ The observed clinical differences between familial and sporadic tremors in this investigation were not caused by the progression of the disease, as the duration of the disease of both groups of patients was similar. The less pronounced symptoms and the involvement of fewer anatomical regions may be a result of the shorter duration of the disease in the senile tremor patients.

We confirmed that there is a slower tremor frequency in senile tremor patients. ${ }^{25}$ The frequency has not been found to be different from patients with essential tremor of the same age. ${ }^{25}$ With increasing age, tremor frequency decreases while the amplitude reportedly increases, ${ }^{37}$ but we did not find higher amplitude in senile tremor patients.

Synchronous (SYN) EMG activity has been reported in $65 \%$ to $95 \%$ of patients with essential, familial, or senile tremor, ${ }^{17,26,38,39}$ while alternating (ALT) activity is seen in only $10 \%$ of patients. ${ }^{40} \mathrm{We}$ found that SYN is more common than ALT, and the alternating activity was more frequent than previously reported. This finding questions the usefulness of EMG examination for the differentiation of essential from Parkinsonian tremor.

Our data did not confirm more frequent ALT in patients with senile tremor. ${ }^{9}$ We found ALT only rarely in familial tremor patients.

Clinical differences between SYN and ALT essential tremor have been found ${ }^{19}$ but not in all reports. ${ }^{17}$ Involvement of both hands, head and facial muscles in SYN tremor patients has been found, while the voice and legs are more commonly involved in ALT tremor patients. ${ }^{19}$ Our results confirmed these data, and we found that the tremor onset was more common from the same anatomical regions. SYN tremor had an earlier involvement of regions outside the limb, after involvement of one limb only. ALT tremor spread to regions outside the limbs later, after involvement of both upper limbs, and frequently also involved the lower limbs. Although it has been reported that SYN tremor more often involves the head and face, ${ }^{19}$ we found more frequent involvement of the head, while ALT involved the chin, tongue and body. 
Rest tremor may normally occur with the progression of essential tremor. ${ }^{41}$ Our data confirmed this finding, and we were able to find rest tremor only in combination with postural, kinetic and intention tremors. It was also the last one to appear. It has been reported that ALT patients have more frequent rest tremor. ${ }^{19}$ We found rest tremor only in ALT patients. Patients with SYN are reported to have postural hands tremor most commonly, ${ }^{19}$ but we found intention tremor more often.

The frequency of ALT tremor has been found to be lower than that of SYN. ${ }^{17,19}$ We confirmed these findings and found higher amplitude and longer burst durations. These differences were not related to the duration of the disease. ALT tremor more frequently involved the lower limbs. Thus ALT tremor shows different clinical and electromyographic features than SYN and, like the familial tremor, is more disabling for patients. Different pathophysiological mechanisms may take part in SYN and ALT tremor. The EMG tremor examination may predict the prognosis of the disease.

\section{REFERENCES}

1. Britton TC. Essential tremor and its variants. Curr Opin Neurol 1995; 8: 314-319.

2. Findley LJ, Koller WC. Definitions and behavioral classifications. In: Findley LJ, Koller WC, eds. Handbook of Tremor Disorders. New York: Marcel Dekker Inc., 1995; 1-5.

3. Larsen TA, Calne DB. Essential tremor. Clin Neuropharmacol 1983; 6: 185-206.

4. Elble RJ. Physiological and essential tremor. Neurology 1986; 36: 225-231.

5. Findley LJ, Cleeves L. Classification of tremor. In: Quinn NP, Jenner PG, eds. Disorders of Movement: Clinical, Pharmacological and Physiological Aspects. London: Academic Press, 1989; 505-519.

6. Sabra AF, Hallet M. Action tremor with alternating activity in antagonist muscles. Neurology (Clev) 1984; 34: 151-156.

7. Lou JS, Jankovic J. Essential tremor: clinical correlates in 350 patients. Neurology 1991; 41: 234-238.

8. Young RR. Essential-familial tremor. In: Vinken PJ, Bruyn GW, Klawans HL, eds. Handbook of Clinical Neurology Vol.5 (49): Extrapyramidal Disorders. Amsterdam: Elsevier Science Publishers, BV, 1986; 565-581.

9. Kachi T, Yamada T, Igata A. Clinical and physiological studies on senile tremor. Nippon Ronen Igakkai Zasshi 1995; 32: 623-627.

10. Lakie M. Is essential tremor physiological? In: Findley LJ, Koller WC, eds. Handbook of Tremor Disorders. New York: Marcel Dekker Inc., 1995; 165-183.

11. Findley LJ. Classification of tremors. J Clin Neurophysiol 1996; 13: 122-132.

12. Marsden CD, Obeso JA, Rothwell JC. Benign essential tremor is not a single entity. In: Yahr MD, ed. Current Concepts of Parkinson's Disease and Related Disorders. Amsterdam: Excerpta Medica, 1983; 31-46.

13. Calzetti S, Baratti M, Gresty M, Findley L. Frequency/amplitude characteristics of postural tremor of the hands in a population of patients with bilateral essential tremor: implications for the classification and mechanism of essential tremor. J Neurol Neurosurg Psychiatry 1987; 50: 561-567.

14. Koller WC, Rubino FA. Combined resting-postural tremors. Arch Neurol 1985; 42: 683-684.

15. Biary N, Koller W. Kinetic predominant essential tremor: successful treatment with clonazepam. Neurology 1987; 37: 471-474.

16. Rapoport A, Sarova I, Braun H. Combined resting-postural tremor of lower limbs: another essential tremor variant. Neurology 1990; 40: 1006.
17. Deuschl G, Lucking $\mathrm{CH}$, Schenck E. Essential tremor: electrophysiological and pharmacological evidence for a subdivision. J Neurol Neurosurg Psychiatry 1987; 50: 1435-1441.

18. Deuschl G, Zimmermann R, Gender H, Lucking CH. Physiological classification of essential tremor. In: Findley LJ, Koller WC, eds. Handbook of Tremor Disorders. New York: Marcel Dekker Inc., 1995; 195-208.

19. Koguchi Y, Nakajima M, Kawamura M, Hirayama K. Clinical subtypes of essential tremor and their electrophysiological and pharmacological differences. Rinsho Shinkeigaku 1995; 35: 132136.

20. Koller WC, Busenbark KL, Dubinsky R, Hubble J. Classification of essential tremor. Clin Neuropharmacol 1992; 15: 81-88.

21. Oldfield RC. The assessment and analysis of handedness: the Edinburgh Inventory. Neuropsychologia 1971; 9: 97-113.

22. Trosch RM, Pullman SL. Botulinum toxin A injections for the treatment of hand tremors. Mov Dis 1994; 9: 601-609.

23. Spieker S, Boose A, Jenigens CH, Dichgans J. Long-term tremor recordings in parkinsonian and essential tremor. J Neural Transm 1995; Suppl. 46: 339-349.

24. Van Hilten JJ, Van Dijk JG, Dinnewold RJW, et al. Diurnal variation of essential and physiological tremor. J Neurol Neurosurg Psychiatry 1991; 54: 516-519.

25. Louis ED, Marder K, Cote L, et al. Differences in the prevalence of essential tremor among elderly African Americans, whites, and Hispanics in northern Manhattan, NY. Arch Neurol 1995; 52: 1201-1205.

26. Hsu YD, Chang MK, Sung SC, Hsein HH, Deng JC. Essential tremor: clinical, electromyographical and pharmacological studies in 146 Chinese patients. Chinese Med J 1990; 45: 93-99.

27. Louis ED, Ottman R. How familial is familial tremor? The genetic epidemiology of essential tremor. Neurology 1996; 46: 12001205.

28. Busenbark K, Barnes P, Lyons K, et al. Accuracy of reported family histories of essential tremor. Neurology 1996; 47: 264-265.

29. Koller WC, Hubble JP, Busenbark KL. Essential tremor. In: Calne DB, ed. Other Neurodegenerative Diseases. Philadelphia: WB Saunders, 1994; 717-742.

30. Koller WC, Biary N. Metoprolol compared with propranolol in the treatment of essential tremor. Arch Neurol 1984; 41: 171-172.

31. Teravainen $\mathrm{H}$, Huttunen $\mathrm{J}$, Lewitt $\mathrm{P}$. Ineffective treatment of essential tremor with an alcohol, methylpentynol. J Neurol Neurosurg Psychiatry 1986; 49: 198-199.

32. Biary N, Koller W. Handedness and essential tremor. Arch Neurol 1985; 42: 1082-1083.

33. Findley LJ, Koller WC. Essential tremor: a review. Neurology 1987; 37: 1194-1197.

34. Koller WC. Treatment of tremor disorders. In: Kurlan R, ed. Treatment of Movement Disorders. J.B. Lippincott Company, 1995; 407-427.

35. Rajput AH, Rozdilsky B, Rajput AH. Essential leg tremor. Neurology 1990; 40: 1909 .

36. Massey EW, Paulson GW. Essential vocal tremor: clinical characteristics and response to therapy. South Med J 1985; 78: 316-317.

37. Elble RJ, Higgins C, Leffler K, Huglus L. Factors influencing the amplitude and frequency of essential tremor. Mov Dis 1994; 9: 589-596.

38. Shahani BT, Young RR. Physiological and pharmacological aids in the differential diagnosis of tremor. J Neurol Neurosurg Psychiatry 1976; 39: 772-783.

39. Henderson JM, Einstein R, Jackson DM, Byth K, Morris JG. 'Atypical' tremor. Eur Neurol 1995; 35: 321-326.

40. Jankovic J, Fahn S. Physiologic and pathologic tremors. Diagnosis, mechanisms and management. Ann Intern Med 1980; 93: 460465.

41. Rajput AH, Rozdilsky B, Ang L, Rajput A. Significance of Parkinsonian manifestations in essential tremor. Can J Neurol Sci 1993; 20: 114-117. 